\title{
Pemanfaatan Qr Code Dalam Pengembangan Sistem Informasi Kehadiran Siswa Berbasis Web
}

\author{
Sri Murni, Raja Sabaruddin \\ ${ }^{[1]}$ Program Studi Manajemen Informatika, AMIK BSI Pontianak \\ ${ }^{[2]}$ Program Studi Komputerisasi Akuntansi, AMIK BSI Pontianak \\ e-mail: ${ }^{[1]}$ Sri.six@bsi.ac.id, ${ }^{[2]}$ raja.rjd@bsi.ac.id
}

\begin{abstract}
ABSTRAK- Kehadiran siswa di sekolah disebut dengan istilah presensi siswa. Presensi siswa mengandung dua makna, yaitu masalah kehadiran dan absennya siswa di sekolah. Kehadiran dan ketidakhadiran siswa di sekolah terkait erat dengan prestasi siswa. Sistem absensi siswa konvensional dapat dikembangkan menjadi sebuah aplikasi dengan memanfaatkan teknologi QR Code. Di mana jauh lebih praktis dan dapat menyampaikan informasi dengan cepat dengan respons yang cepat. Metode yang digunakan dalam pengembangan sistem absensi adalah metode waterfall yang dimulai dari tahap analisis, desain, pengkodean, pengujian dan dukungan. Sedangkan dalam proses pengumpulan data beberapa metode yang dilakukan adalah wawancara, observasi dan studi pustaka. Pengembangan sistem absensi siswa menjadi aplikasi berbasis web yang mampu membantu dan memudahkan guru dalam mencatat data absensi siswa, menghindari proses absensi curang, meningkatkan keamanan data dan mempercepat presensi siswa.
\end{abstract}

Kata Kunci: Situs Web, Presensi, Kode QR

ABSTRACT-The presence of students in the school is called by the term student presence. Understanding student presences contain two meanings, namely the problem of attendance and the absence of students in school. The presence and absence of students in school is closely related to student achievement. The conventional student attendance system can be developed into an application by utilizing $Q R$ Code technology. Where is much more practical and can convey information quickly with fast response. The method used in the development of attendance system is a waterfall that starts from the stage of analysis, design, coding, testing and support. While in the process of collecting data some of the methods undertaken are interviews, observation and literature study. The development of student attendance system into a web-based application is able to help and facilitate the teacher in recording attendance data of students, avoid fraudulent attendance process, improve data security and speed up student absenteeism.

Index Terms : Website, Presence, QR Code

Jurnal Teknologi \& Manajemen Informatika - Vol.4 No.2 2018 


\section{PENDAHULUAN}

\subsection{Latar Belakang}

Teknologi informasi merupakan alat untuk mempermudah, mempercepat, dan merapikan pekerjaan. Hasil dari perkembangan teknologi berupa sistem informasi memungkinkan pekerjaan dapat diselesaikan dengan cepat karena bantuan komputer. Dengan adanya bantuan komputer ini, pekerjaan semakin mudah, rapi dan dengan biaya yang lebih murah dan lebih optimal, namun dapat diandalkan.

Kehadiran siswa di sekolah disebut dengan istilah presensi siswa. Pengertian presensi siswa mengandung dua arti, yaitu masalah kehadiran dan ketidak hadiran siswa di sekolah. Kehadiran dan ketidak hadiran siswa di sekolah memegang peranan penting dalam peroses belajar mengajar, karena hal ini sangat erat hubungannya dengan prestasi belajar siswa. Misalnya dalam proses belajar mengajar, siswa yang hadir memiliki rasa tanggungjawab untuk mengikuti pelajaran yang sedang berlangsung sesuai dengan tingkatan dan mengikuti kegiatan-kegitan di sekolah sekaligus untuk mengontrol kerajinan belajar mereka. Di samping itu, kehadiran dan ketidak hadiran siswa di sekolah mempermudah para pengajar melalukan rekapitulasi data kehadiran.

Pada umumnya, sekolah-sekolah yang ada di Indonesia masih menggunakan absensi secara konvensional. Pada proses pencatatan dan peroses rekapitulasi kehadiran siswa masih menggunakan sistem manual, yaitu pengajar memanggil satu persatu siswa pada lembar absensi yang telah disediakan sesuai dengan nama masing-masing siswa, bisa juga dengan membagi lembar absensi dan meminta siswa untuk mengisi secara manual. Aktifitas seperti ini menimbulkan beberapa permasalahan bagi pengajar yaitu siswa dapat memanipulasikan pencatatan kehadiran tersebut dan proses yang dilakukan cukup membutuhkan waktu yang lama sehingga cara seperti ini tidak efektif dan kurang akurat.

Berkaitan dengan makin maraknya perkembangan teknologi, dimana salah satunya penggunaan barcode atau kode batang yang merupakan implementasi teknologi yang lazin digunakan dalam dunia jual beli. Bahkan tidak cukup dengan kecanggihan barcode yang mudah discan, kini kecanggihan teknologi menghadirkan QR Code yang merupakan bentuk evolusi barcode dari satu dimensi menjadi dua dimensi. QR Code jauh lebih praktis dan mempunyai banyak keunggulan daripada barcode. Qr Code (Quick Response Code) yang berarti kode yang bisa menyampaikan informasi secara cepat dengan perolehan respon yang cepat pula.

Pemanfaatan QR Code dalam pemgembangan sistem informasi kehadiran siswa yang akan dikembangkan oleh penulis berbentuk sebuah aplikasi berbasis web. Diharapkan aplikasi yang dibangun dapat memudahkan dan mempercepat pekerjaan rekapitulasi absen siswa, sehingga lebih optimal, efektif, dan efisien.

\subsection{Tujuan}

Penelitian ini bertujuan untuk mengembangkan sistem informasi kehadiran siswa berbentuk sebuah aplikasi berbasis web dengan memanfaatkan implementasi teknologi berupa QR Code.

\subsection{Ruang Lingkup}

Aplikasi presensi yang dibangun ditujukan untuk tenaga pengajar dan siswa. Dimana mencakup pengolahan data guru, mata pelajaran, jadwal pelajaran, jadwal mengajar, data kelas, data siswa, presensi guru dan siswa serta pembuatan kartu siswa dan nametag guru yang menyertakan $Q R$ Code. Metode yang digunakan dalam pengembangan sistem informasi kehadiran siswa ini adalah waterfall.

\section{TINJAUAN PUSTAKA \\ 2.1 Internet}

Menurut Soetejo (2012:1) “Internet (kependekan dari interconnection-networking) ialah sistem global dari seluruh jaringan komputer yang saling terhubung menggunakan standar internet Protocol Suite(TCP/IP) untuk melayani miliaran pengguna di seluruh dunia". 


\subsection{Website}

Selain itu juga web merupakan sistem yang erat kaitanya dengan dokumen sebagai media untuk menampilkan hasil berupa teks, gambar, multimedia dan lainnya di jaringan internet (Sibero, 2014:11).

\subsection{PHP}

PHP adalah salah satu bahasa pemrograman yang berjalan dalam sebuah web server dan berfungsi sebagai pengolah data pada sebuah server (Madcoms dan Andi, 2008).

\subsection{HTML}

HTML adalah bahasa yang harus dipahami dalam pembuatan website. Menurut Badiyanto (2013:23) HTML(Hyper Text Markup Langguage) merupakan bahasa standar pemrograman untuk membuat halaman web yang terdiri dari kode-kode tag tertentu, kemudian kode-kode tersebut diterjemahkan oleh web browser untuk menampilkan halaman web yang terdiri dari berbagai macam format tampilan seperti teks, grafik, animasi link, maupun audiovidio.bahasa standar untuk membuat halamanhalaman web.

\subsection{MySQL}

MySQL (My Structure Query langguage) merupakan Database Management System (DBMS) yang berfungsi untuk mengolah basis data menggunakan SQL (Anhar, 2010:45).

\subsection{QR Code}

Qr Code, kependekan dari Quick Response Code, merupakan gambar dua dimensi yang memiliki kemampuan untuk menyimpan data, baik berupa data teks, numerik, alfanumerik manupun kode benner (Nugraha dan Munir, 2011:148).

\subsection{Metode Waterfall}

Pembangunan aplikasi menggunakan metode SDLC waterfall. Berikut ini akan dijelas- kan pengertian dari SDLC waterfall (Systems Development Life Cycle) yang merupakan siklus hidup pengembangan sistem.

Model SDLC air terjun (waterfall) sering juga disebut model sekuensial linier (sequential linear) atau alur hidup klasik (classic life cycle). Model alur terjun menyediakan pendekatan alur hidup perangkat lunak secara sekuensial atau terurut dimulai dari analisa, desain, pengodean, pengujian dan tahap pendukung (support) (Rosa dan Shalahuddin, 2014:28).

Model air terjun sangat cocok digunakan kebutuhan pelanggan sudah sangat dipahami dan kemungkinan terjadinya perubahan kebutuhan selama pengembangan perangkat lunak kecil. Hal positif dari model air terjun adalah struktur tahap pengembangan sistem jelas, dokumentasi dihasilkan di setiap tahap pengembangan, dan sebuah tahap dijalankan setelah tahap sebelumnya selesai dijalankan (tidak ada tumpang tindih pelaksanaan tahap). Rosa dan Shalahuddin (2014:30-31).

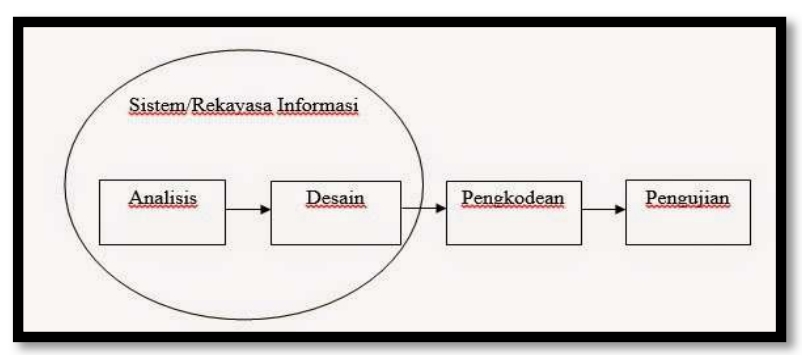

Sumber : Rosa dan Shalahuddin (2014:29)

Gambar 2.1.Metode Waterfall

\section{METODOLOGI}

Dalam pembangan sistem menjadi sebuah aplikasi, ada 2 metode yang dilakukan oleh penulis yaitu:

\subsection{Metode Pengembangan Software}

Untuk model pengembangan perangkat lunak, penulis menggunakan model Waterfall (Shalahuddin, 2013:28) yang dibagi menjadi empat tahapan, yaitu:

1. Analisa Kebutuhan Perangkat Lunak

Proses pengumpulan kebutuhan dilakukan secara intensif untuk menspesifikasikan kebutuhan perangkat lunak agar dapat 
dipahami perangkat lunak seperti apa yang dibutuhkan oleh user. Pada proses analisa kebutuhan perangkat lunak penulis memperoleh kebutuhan dengan cara tanya jawab, observasi dan dokumentasi melalui bagian kurikulum dan staf tata usaha.

2. Desain

Desain perangkat lunak adalah proses multi langkah yang fokus pada desain pembuatan program perangkat lunak termasuk struktur data, arsitektur perangkat lunak, representasi antarmuka, dan prosedur pengkodean. Setelah melakukan tahap analisa kebutuhan, tahap selanjutnya yaitu desain. Pada tahap ini penulis mencoba merancang antarmuka pemakai aplikasi. Dimana website yang akan dibuat sesuai dengan prosedur yang telah dianalisa, sebagai contoh merancang halaman utama website, merancang database dan tools apa saja yang dibutuhkan dalam proses pembuatannya.

3. Pembuatan Kode Program

Desain harus ditranslasikan ke dalam program perangkat lunak. Hasilnya adalah program komputer sesuai dengan desain yang telah dibuat pada tahap desain. Pada tahap ini penulis melakukan pengkodean website dengan software Dreaemweaver 8.0, selain itu juga database editor yang penulis gunakan adalah SQLyog Enterprise 8.18. Pengkodean penulis buat berdasarkan rancangan yang telah di buat di tahap desain.

\section{Pengujian}

Pengujian fokus pada perangkat lunak secara dari segi lojik dan fungsional dan memastikan bahwa semua bagian sudah diuji. Hal ini dilakukan untuk meminimalisir kesalahan dan memastikan keluaranyang dihasilkan sesuai dengan yang diinginkan. Agar website yang di buat penulis memberikan hasil yang aktual sesuai kebutuhan, maka penulis melakukan pengujian dengan cara black box testing yaitu dengan mengamati hasil eksekusi data uji dan fungsional perangkat lunak khususnya pada input dan output website (apakah sudah sesuai dengan apa yang diharapkan atau belum).

\subsection{Metode Pengumpulan Data} adalah:

Teknik pengumpulan data yang digunakan

1. Wawancara (Interview)

Untuk mendapatkan informasi secara lengkap maka penulis melakukan metode tanya jawab dengan bagian kurikulum dan staf tata usaha mengenai semua kegiatan yang berhubungan dengan kehadiran siswa.

\section{Pengamatan (Observation)}

Melakukan pengamatan-pengamatan langsung terhadap kegiatan yang berhubungan dengan masalah yang diambil. Hasil dari pengamatan di tersebut langsung dapat diketahui kesalahan atau proses dan kegiatan tersebut.

3. Studi pustaka

Selain melakukan kegiatan di atas penulis juga melakukan studi kepustakaan melalui literatur-literatur atau referensi-referensi buku, jurnal, berita dan artikel yang berhubungan dengan penelitian baik dari perpustakaan maupun internet.

\section{PEMBAHASAN}

4.1 Analisa Kebutuhan

Analisa kebutuhan fungsional di bagi menjadi dua, yaitu kebutuhan fungsional dan non fungsional.

1. Kebutuhan Fungsional

a. Sistem dapat memberikan informasi data profil guru dan siswa.

b. Sistem dapat memberikan layanan informasi data kelas, mata pelajaran, prodi, tahun ajaran, dan jadwal mengajar guru.

c. Sistem dapat memberikan informasi kehadiran siswa yang hadir, sakit, izin, dan tidak hadir.

d. Sistem dapat memberikan layanan cetak rekap kehadiran berdasarkan mata pelajaran. 
e. Sistem dapat memberikan layanan cetak kartu siswa yang digunakan untuk melakukan proses presensi.

Dari hasil analisa di atas, dibutuhkan sistem informasi yang bermanfaat bagi guru terutama dalam dalam pembuatan laporan kehadiran siswa.

2. Kebutuhan Non Fungsional

a. Perangkat Keras

Untuk merancang dan membuat sistem kehadiran siswa berbasis web di butuhkan perangkat keras agar program aplikasi yang di buat dapat berjalan baik. Adapun perangkat keras yang di gunakan adalah sebagai berikut :

1) CPU $2,6 \mathrm{Ghz}$

2) Hardisk $80 \mathrm{~GB}$

3) RAM 512GB-1GB

4) VGA $128 \mathrm{~GB}$

5) Monitor 15 "

6) Webcam

b. Perangkat Lunak

Pernagkat lunak yang digunakan untuk mendukung dan merancang pembuatan sistem informasi kehadiran berbasis website harus sesuai dengan kebutuhan. Perangkat lunak yang di gunakan adalah sebagai berikut :

1) Sistem Operasi Windows 7 atau Windows 8

2) Menggunakan Apache Web Server

3) MySQL Server sebagai database editor

4) Google Chrome sebagai web browser

5) Dreamweaver CS5 sebagai media web editor

c. Perangkat Manusia

Sebagai pelaksana dari sistem yang di usulkan adalah:

1) Admin

Bertugas mengoperasikan sistem yang telah di buat, meliputi proses input, pengeditan, penghapusan dan pemiliharaan data.
2) Guru

Bertugas mengoperasikan sistem yang telah di buat, meliputi proses pembuatan cetak kehadiran dan melakukan pengeditan presensi kehadiran.

3) Siswa

Siswa diperlukan untuk melakukan proses absensi.

4) Teknisi

Teknisi diperlukan untuk memilihara perangkat keras dan perangkat lunak yang mendukung aplikasi, merawat dari kerusakan dan merawat perangkat lunak

\subsection{Tahap Desain}

1. ERD

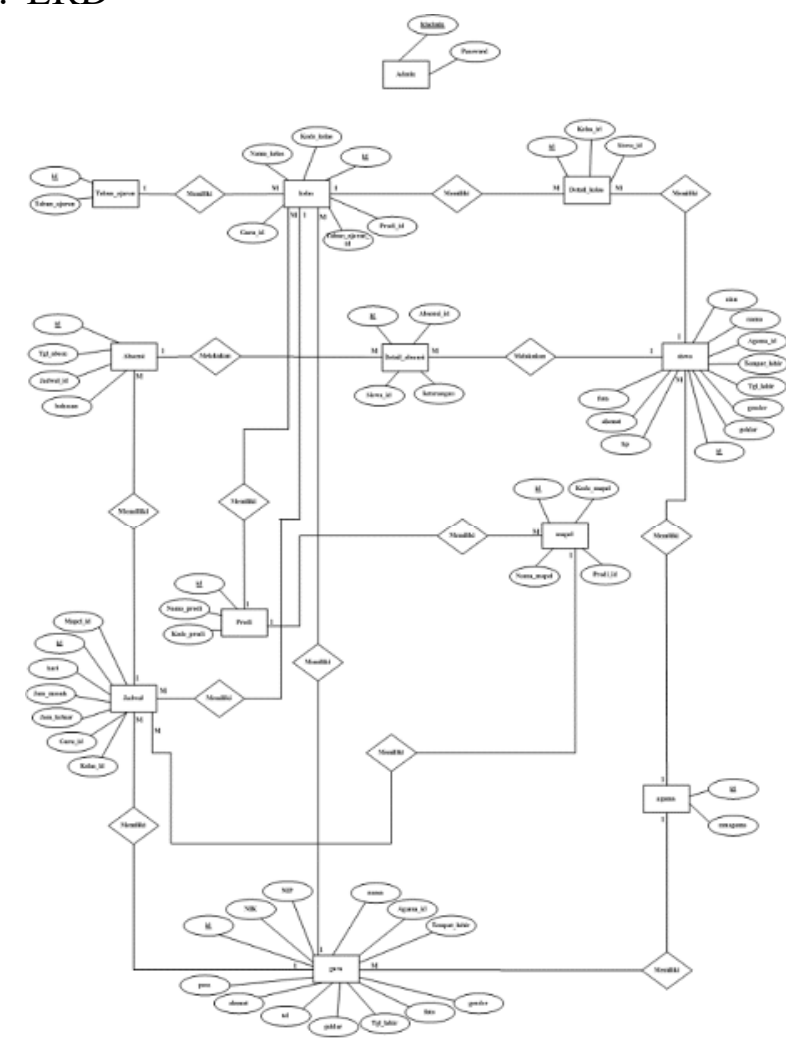

Gambar 4.1 ERD Sistem Informasi Kehadiran Siswa 
2. LRS

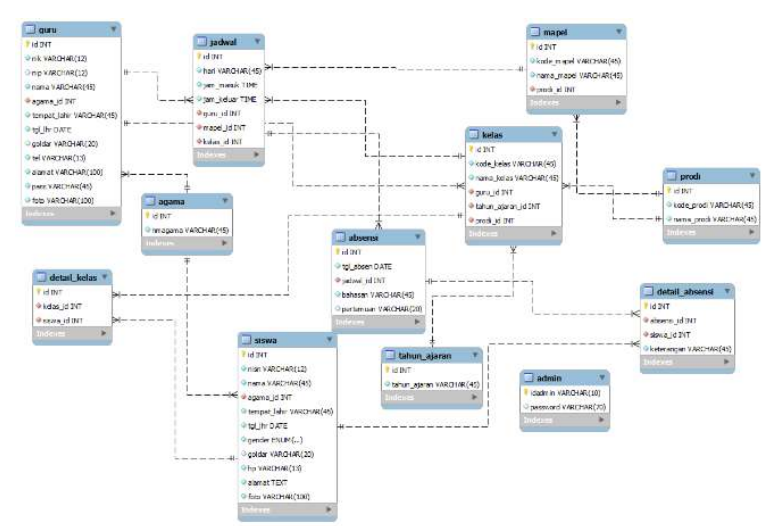

Gambar 4.2 LRS Sistem Informasi Kehadiran Siswa

3. Spesifikasi File

a. Spesifikasi Tabel Admin

Tabel III.1.

Spesifikasi File Admin

\begin{tabular}{|l|l|l|l|l|l|}
\hline No & $\begin{array}{l}\text { Elemen } \\
\text { Data }\end{array}$ & $\begin{array}{l}\text { Nama } \\
\text { Field }\end{array}$ & Tipe & Size & Ket \\
\hline 1 & $\begin{array}{l}\text { ID Ad- } \\
\text { min }\end{array}$ & Idadmin & Varchar & 10 & $P K$ \\
\hline 2 & Password & Password & Varchar & 70 & \\
\hline
\end{tabular}

b. Spesifikasi Tabel Guru

Tabel III.2

Spesifikasi File Guru

\begin{tabular}{|l|l|l|l|l|l|}
\hline No & $\begin{array}{l}\text { Elemen } \\
\text { Data }\end{array}$ & $\begin{array}{l}\text { Nama } \\
\text { Field }\end{array}$ & Tipe & Size & Ket \\
\hline 1 & ID Guru & Id & int & 11 & $\begin{array}{l}P K, \\
A I\end{array}$ \\
\hline 2 & NIK & nik & Varchar & 12 & \\
\hline 3 & NIP & nip & Varchar & 12 & \\
\hline 4 & Nama & Nama & Varchar & 45 & \\
\hline 5 & Agama & Agama & Int & 11 & FK \\
\hline 6 & $\begin{array}{l}\text { Jenis } \\
\text { kelamin }\end{array}$ & Gender & Enum & $\begin{array}{l}\text { 'Laki- } \\
\text { laki',p } \\
\text { eremp } \\
\text { uan' }\end{array}$ & \\
\hline 7 & $\begin{array}{l}\text { Tempat } \\
\text { Lahir }\end{array}$ & $\begin{array}{l}\text { Tempat_I } \\
\text { ahir }\end{array}$ & Varchar & 45 & \\
\hline 8 & $\begin{array}{l}\text { Tanggal } \\
\text { lahir }\end{array}$ & Tgl_lahir & Date & & \\
\hline 9 & $\begin{array}{l}\text { Golongan } \\
\text { darah }\end{array}$ & Goldar & Varchar & 20 & \\
\hline
\end{tabular}

\begin{tabular}{|l|l|l|l|l|l|}
\hline 10 & Telphon & Telp & Varchar & 13 & \\
\hline 11 & Alamat & Alamat & Varchar & 100 & \\
\hline 12 & Password & Password & Varchar & 45 & \\
\hline 12 & Foto & foto & Varchar & 100 & \\
\hline
\end{tabular}

c. Spesifikasi Tabel Siswa

Tabel III.3

Spesifikasi File Siswa

\begin{tabular}{|c|c|c|c|c|c|}
\hline No & $\begin{array}{l}\text { Elemen } \\
\text { Data }\end{array}$ & $\begin{array}{l}\text { Nama } \\
\text { Field }\end{array}$ & Tipe & Size & Ket \\
\hline 1 & ID & Id & int & 11 & $\begin{array}{l}P K, \\
A l\end{array}$ \\
\hline 2 & NIS & nisn & Varchar & 12 & \\
\hline 4 & Nama & Nama & Varchar & 45 & \\
\hline 5 & Agama & Agama & Int & 11 & $F K$ \\
\hline 6 & $\begin{array}{l}\text { Jenis } \\
\text { kelamin }\end{array}$ & Gender & Enum & $\begin{array}{l}\text { 'Laki- } \\
\text { laki','p } \\
\text { eremp } \\
\text { uan' }\end{array}$ & \\
\hline 7 & $\begin{array}{l}\text { Tempat } \\
\text { Lahir }\end{array}$ & $\begin{array}{l}\text { Tempat } \\
\text { _lahir }\end{array}$ & Varchar & 45 & \\
\hline 8 & $\begin{array}{l}\text { Tanggal } \\
\text { lahir }\end{array}$ & Tgl_lahir & Date & & \\
\hline 9 & $\begin{array}{l}\text { Golongan } \\
\text { darah }\end{array}$ & Goldar & Varchar & 20 & \\
\hline 10 & Telphon & $\mathrm{hp}$ & Varchar & 13 & \\
\hline 11 & Alamat & Alamat & Text & & \\
\hline 12 & Foto & Foto & Varchar & 100 & \\
\hline
\end{tabular}

d. Spesifikasi Tabel Agama

Tabel III.4

Spesifikasi File Agama

\begin{tabular}{|c|l|l|l|l|l|}
\hline No & $\begin{array}{l}\text { Elemen } \\
\text { Data }\end{array}$ & $\begin{array}{l}\text { Nama } \\
\text { Field }\end{array}$ & Tipe & Size & Ket \\
\hline 1 & ID Agama & Id & Varchar & 11 & $P K$ \\
\hline 2 & $\begin{array}{l}\text { Nama } \\
\text { Agama }\end{array}$ & $\begin{array}{l}\text { Nmag } \\
\text { ama }\end{array}$ & Varchar & 45 & \\
\hline
\end{tabular}

e. Spesifikasi Tabel Jadwal

Tabel III.5

Spesifikasi File Jadwal

\begin{tabular}{|c|c|c|c|c|c|}
\hline$N$ & $\begin{array}{l}\text { Elemen } \\
\text { Data }\end{array}$ & $\begin{array}{l}\text { Nama } \\
\text { Field }\end{array}$ & Tipe & Size & Ket \\
\hline 1 & ID jadwal & Id & Varchar & 11 & $P K$ \\
\hline
\end{tabular}




\begin{tabular}{|l|l|l|l|l|l|}
\hline 2 & Nama Hari & Hari & Varchar & 45 & \\
\hline 3 & Jam Masuk & $\begin{array}{l}\text { Jam_ma } \\
\text { suk }\end{array}$ & Time & & \\
\hline 4 & Jam Keluar & $\begin{array}{l}\text { Jam_kel } \\
\text { uar }\end{array}$ & Time & & \\
\hline 5 & Nama Guru & Guru_id & Int & 11 & FK \\
\hline 6 & $\begin{array}{l}\text { Nama Mata } \\
\text { pelajaran }\end{array}$ & $\begin{array}{l}\text { Mapel_i } \\
\text { d }\end{array}$ & Int & 11 & FK \\
\hline 7 & Nama Kelas & Kelas_id & Int & 11 & FK \\
\hline
\end{tabular}

\section{f. Spesifikasi Tabel Kelas}

Tabel III.6

Spesifikasi File Kelas

\begin{tabular}{|l|l|l|l|l|l|}
\hline No & $\begin{array}{l}\text { Elemen } \\
\text { Data }\end{array}$ & Nama Field & Tipe & Size & Ket \\
\hline 1 & ID Kelas & Id & Int & 11 & $P K$ \\
\hline 2 & $\begin{array}{l}\text { Kode } \\
\text { Kelas }\end{array}$ & Kode_kelas & Varchar & 45 & \\
\hline 3 & $\begin{array}{l}\text { Nama } \\
\text { Kelas }\end{array}$ & Nama_kelas & Varchar & 45 & \\
\hline 4 & $\begin{array}{l}\text { Nama } \\
\text { Guru }\end{array}$ & Guru_id & Int & 11 & $F K$ \\
\hline 5 & $\begin{array}{l}\text { Tahun } \\
\text { Ajaran }\end{array}$ & $\begin{array}{l}\text { Tahun_ajara } \\
\text { n_id }\end{array}$ & Int & 11 & $F K$ \\
\hline 6 & Prodi & Prodi_id & Int & 11 & $F K$ \\
\hline
\end{tabular}

g. Spesifikasi Tabel Detail Kelas

Tabel III.7

Spesifikasi File Detail Kelas

\begin{tabular}{|c|l|l|l|l|l|}
\hline No & Elemen Data & $\begin{array}{l}\text { Nama } \\
\text { Field }\end{array}$ & Tipe & Size & Ket \\
\hline 1 & $\begin{array}{l}\text { ID Detai } \\
\text { Kelas }\end{array}$ & Id & Int & 11 & $P K$ \\
\hline 2 & Kelas & Kelas_id & Int & 11 & $F K$ \\
\hline 3 & Nama Siswa & Siswa_id & Int & 11 & $F K$ \\
\hline
\end{tabular}

h. Spesifikasi Tabel Mata Pelaran

Tabel III. 8

Spesifikasi File Detail Kelas

\begin{tabular}{|c|l|l|l|l|l|}
\hline $\begin{array}{l}\text { N } \\
\text { o }\end{array}$ & $\begin{array}{l}\text { Elemen } \\
\text { Data }\end{array}$ & $\begin{array}{l}\text { Nama } \\
\text { Field }\end{array}$ & Tipe & $\begin{array}{l}\text { Siz } \\
\mathrm{e}\end{array}$ & Ket \\
\hline 1 & $\begin{array}{l}\text { ID Mata } \\
\text { pelajaran }\end{array}$ & Id & Int & 11 & $P K$ \\
\hline 2 & $\begin{array}{l}\text { Kode Mata } \\
\text { pelajaran }\end{array}$ & $\begin{array}{l}\text { Mapel_i } \\
\text { d }\end{array}$ & $\begin{array}{l}\text { Varcha } \\
\text { r }\end{array}$ & 45 & $F K$ \\
\hline 3 & $\begin{array}{l}\text { Nama Mata } \\
\text { pelajaran }\end{array}$ & $\begin{array}{l}\text { Mapel_i } \\
\text { d }\end{array}$ & $\begin{array}{l}\text { Varcha } \\
\mathrm{r}\end{array}$ & 45 & $F K$ \\
\hline
\end{tabular}

\begin{tabular}{|l|l|l|l|l|l|}
\hline 4 & Nama Prodi & $\begin{array}{l}\text { Prodi_i } \\
\text { d }\end{array}$ & Int & 11 & FK \\
\hline
\end{tabular}

i. Spesifikasi Tabel Prodi

Tabel III.9

Spesifikasi File Prodi

\begin{tabular}{|c|l|l|l|l|l|}
\hline $\begin{array}{l}\text { N } \\
\text { o }\end{array}$ & $\begin{array}{l}\text { Elemen } \\
\text { Data }\end{array}$ & $\begin{array}{l}\text { Nama } \\
\text { Field }\end{array}$ & Tipe & Size & Ket \\
\hline 1 & ID Prodi & Id & Int & 11 & $\begin{array}{l}P K \\
\text { II }\end{array}$ \\
\hline 2 & $\begin{array}{l}\text { Kode } \\
\text { prodi }\end{array}$ & $\begin{array}{l}\text { Kode_ } \\
\text { prodi }\end{array}$ & Varchar & 45 & \\
\hline 3 & $\begin{array}{l}\text { Nama_pro } \\
\text { di }\end{array}$ & Level & Varchar & 45 & \\
\hline
\end{tabular}

j. Spesifikasi Tabel Tahun Ajaran

Tabel III.10

Spesifikasi File Tahun Ajaran

\begin{tabular}{|l|l|l|l|l|l|}
\hline No & $\begin{array}{l}\text { Elemen } \\
\text { Data }\end{array}$ & $\begin{array}{l}\text { Nama } \\
\text { Field }\end{array}$ & Tipe & Size & Ket \\
\hline 1 & $\begin{array}{l}\text { ID Tahun } \\
\text { Ajaran }\end{array}$ & Id & Int & 11 & $P K$ \\
\hline 2 & $\begin{array}{l}\text { Tahun } \\
\text { Ajaran }\end{array}$ & $\begin{array}{l}\text { Tahun_aja } \\
\text { ran }\end{array}$ & Varchar & 45 & \\
\hline
\end{tabular}

k. Spesifikasi Tabel Absensi

Tabel III.11

Spesifikasi File Absensi

\begin{tabular}{|c|l|l|l|l|l|}
\hline No & $\begin{array}{l}\text { Elemen } \\
\text { Data }\end{array}$ & Nama Field & Tipe & Size & Ket \\
\hline 1 & ID absen & Id & Int & 11 & $P K$ \\
\hline 2 & $\begin{array}{l}\text { Tanggal } \\
\text { Absen }\end{array}$ & Tgl_absen & Date & & \\
\hline 3 & Jadwal & Jadwal_id & Int & 11 & $F K$ \\
\hline 4 & Bahasan & Bahasan & Varchar & 45 & \\
\hline 5 & Pertemuan & Pertemuan & Varchar & 20 & \\
\hline
\end{tabular}

1. Spesifikasi Tabel Detail Absensi

Tabel III.12

Spesifikasi File Detail Absensi

\begin{tabular}{|c|l|l|l|l|l|}
\hline No & $\begin{array}{l}\text { Elemen } \\
\text { Data }\end{array}$ & Nama Field & Tipe & $\begin{array}{l}\text { Siz } \\
\mathrm{e}\end{array}$ & Ket \\
\hline 1 & $\begin{array}{l}\text { ID Detail } \\
\text { Absensi }\end{array}$ & Id & Int & 11 & $P K$ \\
\hline 2 & Absen & Absen_id & Int & 11 & $F K$ \\
\hline 3 & $\begin{array}{l}\text { Nama } \\
\text { Siswa }\end{array}$ & Siswa_id & Int & 11 & $F K$ \\
\hline
\end{tabular}




\begin{tabular}{|l|l|l|l|l|l|}
\hline 4 & $\begin{array}{l}\text { Keteranga } \\
\mathrm{n}\end{array}$ & Keterangan & Varchar & 45 & \\
\hline
\end{tabular}

4. Struktur Navigasi

a. Struktur Navigasi Halaman Admin

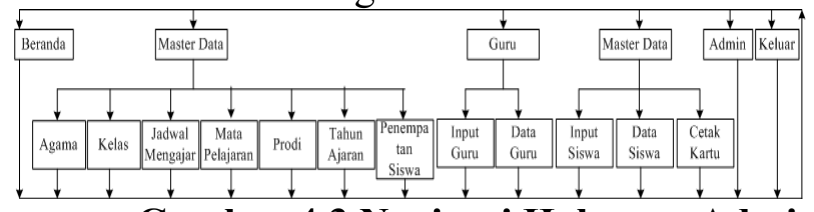

Gambar 4.3 Navigasi Halaman Admin

b. Struktur Navigasi Halaman Guru

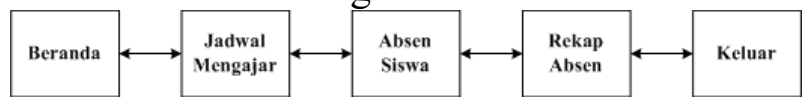

Gambar 4.3 Navigasi Halaman Guru

\subsection{Tahap Implementasi}

1. Rancangan Antarmuka

\section{a. Halaman Utama Admin}

Halaman admin digunakan untuk pengolahan data. Yaitu, menu beranda, master data, guru, siswa, admin dan logout. Menu beranda berisi informasi selamat datang untuk admin, menu master data berisi beberapa pilihan menu yaitu agama, kelas, jadwal pelajaran, mata pelajaran. prodi, dan tahun ajaran, menu guru berisi informasi pengolahan data guru, menu admin berisikan informasi pengolahan data admin sedangkan logout berfungsi untuk keluar dari halaman admin.

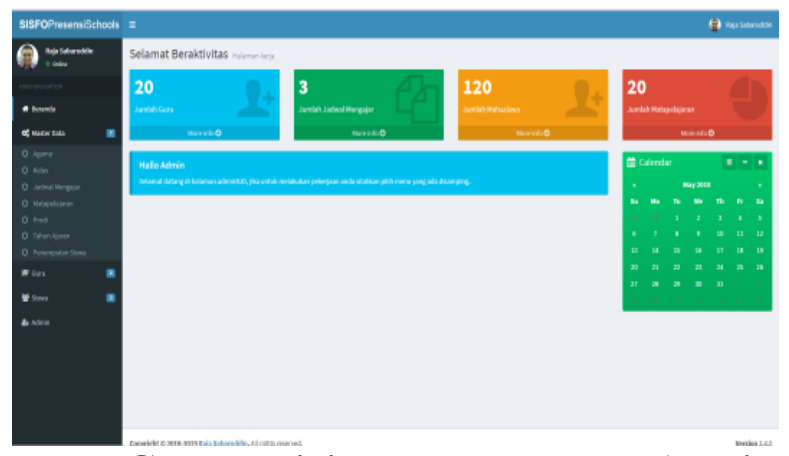

Gambar 4.4 Halaman Utama Admin

\section{b. Halaman Utama Guru}

Pada Halaman guru tersedia beberapa menu yaitu, Beranda, Profil, Jadwal Mengajar, Absen Siswa, Rekap Bahasan, dan Laporan Absen Siswa. Menu profil berisi informasi data guru yang bersangkutan, menu jadwal mengajar berisikan informasi jadwal mengajar guru, menu absen siswa berisi informasi kegiatan guru mengabsen siswa berdasarkan kelas yang diajar pada hari tersebut, menu rekap bahasan berisikan tentang informasi rekapitulasi bahasan ajar setiap pertemuan sedangkan menu laporan absen siswa berisikan informasi tentang laporan data absen siswa.

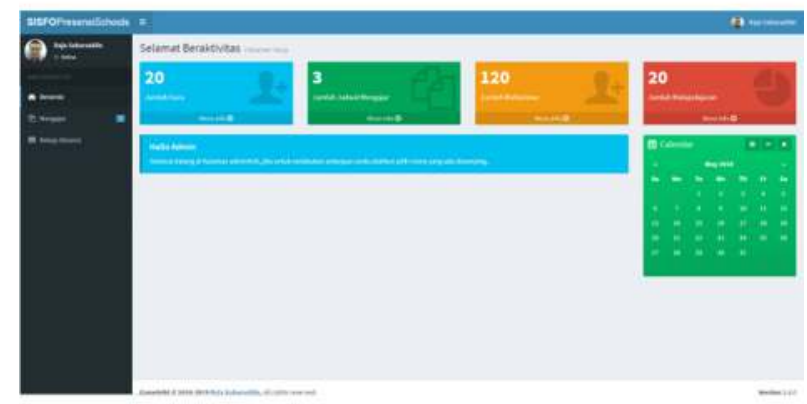

\section{Gambar 4.5 Halaman Utama Guru}

\section{c. Halaman Presensi}

Halaman presensi ini merupakan bagian utama dari aplikasi yang digunakan untuk proses absensi siswa yang hadir, tidak hadir, sakit dan izin.

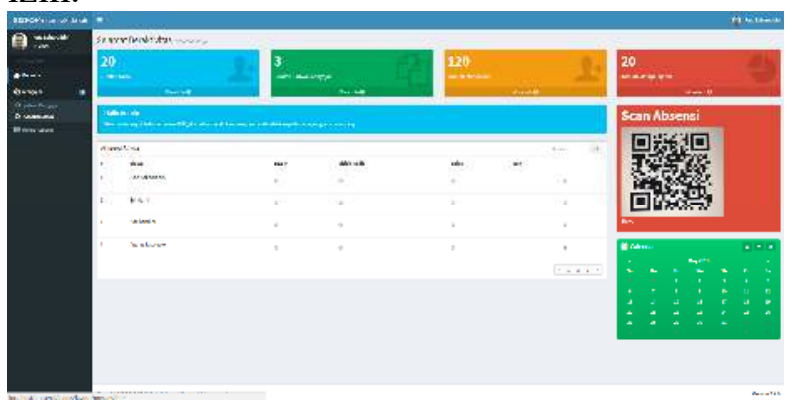

Gambar 4.6 Halaman Presensi

\section{d. Kartu Pelajar}

Kartu pelajar didesain seperti bentuk kartu pelajar pada umumnya, yang berisi data pelajar. Hanya terdapat penambahan QR Code untuk melakukan absen. 


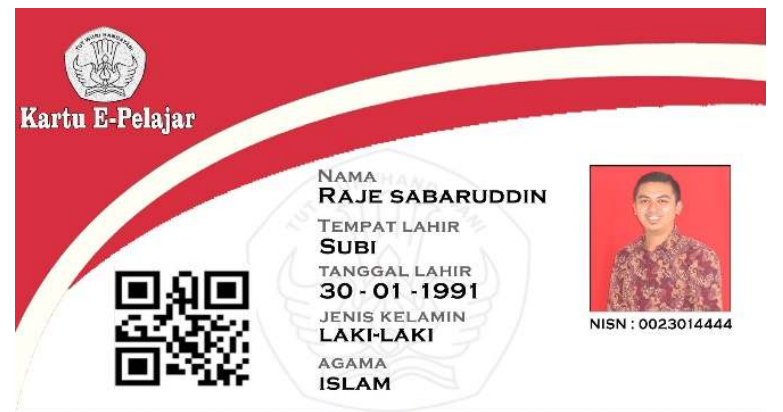

Gambar 4.7 Kartu Pelajar

\section{Spesifikasi Sistem Komputer}

a. Spesifikasi Perangkat Keras

1) Server

a) $\mathrm{CPU}$

- Processor GHz

- RAM DDR2 4 GB

- Hardisk 500 GB

b) Mouse

c) Keyboard

d) Monitor dengan resolusi layar minimum $1024 \times 768$

e) Koneksi internet dengan kecepatan 2 Mbps

2) Client
a) $\mathrm{CPU}$
- Processor $\mathrm{GHz}$
- RAM DDR2 1 GB
- Hardisk 20 GB
b) Mouse
c) Keyboard
d) Monitor dengan resolusi layar minimum $1024 \times 768$
e) Koneksi internet dengan kecepatan $56 \mathrm{kbps}$

b. Spesifikasi Perangkat Lunak

1) Server

a) Sistem operasi yang digunakan adalah Microsoft Windows 7 dan Windows 8.

b) Aplikasi bundle web server yaitu WAMP, XAMPP, php2tiad yang terdiri dari komponen, diantaranya :

- Apliaksi Apache Server v2

- Aplikasi PHP Sever v5

- Apliaksi MySQL Server v5
- Aplikasi phpmyadmin v3

c) Aplikasi lihat seperti Mozzila Firefox, Opera, Safari, Internet Explorer, Google Chrome.

2) Client

a) Sistem operasi yang digunakan adalah Microsoft Windows 7 dan Windows 8.

b) Aplikasi lihat seperti Mozzila Firefox, Opera, Safari, Internet Explorer, Google Chrome.

\subsection{Black Box Testing}

\section{Pengujian Terhadap Form Login Admin}

Pengujian ini berfungsi untuk mengecek apakah pengguna berhasil masuk ke sistem atau tidak. Dimana pengguna diharuskan untuk memasukkan id admin dan password yang benar agar dapat masuk ke sistem. Pesan akan tampil jika pengguna tidak memasukkan atau salah memasukkan id admin dan password.

\section{Pengujian Terhadap Form Login Guru}

Kinerja form login guru sama dengan form login admin yang berfungsi untuk mengecek apakah guru berhasil masuk ke sistem atau tidak. Dimana guru diharuskan untuk memasukkan id guru dan password yang benar agar dapat masuk ke sistem. Pesan akan tampil jika guru tidak memasukkan atau salah memasukkan id guru dan password.

\section{Pengujian Terhadap Halaman Utama Admin}

Pengguna dapat mengakses halaman ini jika sudah berhasil masuk ke sistem. Halaman ini menampilkan beberapa menu yaitu menu master (kelas, mata pelajaran, jadwal, prodi, dan tahun ajaran, penempatan siswa), menu guru, menu siswa (pengolahan data siswa dan cetak kartu pelajar), menu admin (pengolahan data admin) dan menu keluar. Dari hasil pengujian semua fitur berjalan dengan baik (valid).

\section{Pengujian Terhadap Halaman Utama Guru \\ Pengujian terhadap halaman ini dimaksudkan untuk mengecek apakah semua fitur berjalan}


dengan baik dan sesuai harapan. Dimana pada halaman ini guru dapat mengakses beberapa fitur menu dan melakukan pengolahan data di dalamnya. Menu halaman guru terdiri dari menu jadwal mengajar, absen siswa, rekap absen, dan menu keluar. Hasil dari pengujian berjalan dengan baik dan sesuai harapan (valid).

\section{Pengujian Terhadap Halaman Presensi}

Pengujian dilakukan untuk mengecek apakah halaman presensi atau absen kehadiran siswa valid atau tidak. Dimana pada halaman ini proses absensi menggunakan QR Code yang terdapat pada kartu pelajar. Selain itu guru dapat melakukan perubahan data absen apabila ketidakhadiran siswa karena alasan ijin atau sakit. Dari hasil pengujian, halaman ini berjalan dengan baik dan sesuai harapan (valid).

\section{KESIMPULAN}

Dalam pengembangan sistem informasi kehadiran siswa atau presensi siswa dengan menggunakan metode waterfall dapat disimpulkan bahwa:

1. Pengembangan sistem informasi kehadiran menjadi sebuah aplikasi dapat membantu dan memudahkan guru dalam mengolah dan mengakses data kehadiran siswa.

2. Aplikasi presensi dengan memanfaatkan $\mathrm{QR}$ Code jauh lebih praktis dan dapat menyimpan informasi secara cepat dengan respon yang cepat.

3. Aplikasi presensi berbasis web dimaksudkan agar pengguna dapat mengakses data yang berkaitan dengan kehadiran dimanapun dan kapanpun karena dalam praktiknya guru terbiasa melakukan pengisian raport di rumah. Dengan demikian akan memudahkan guru dalam mengakses rekap absen.

4. Mempercepat proses perekapan data kehadiran.

5. Menghindari kecurangan dalam proses absen.

6. Tingkat keamanan data tinggi karena menggunakan database sebagai media penyimpanan data.

\section{DAFTAR REFERENSI}

[1] Annhar. 2010. Panduan Menguasai PHP dan MySQL Secara Otodidak. Jakarta: MediaKita.

[2] Badiyanto. 2013. Buku Pintar Framework Yii. Yogyakarta: PT Buku Seru

[3] Sibero, Alexander, F, K. 2013. Web Programming Power Pack. Yogyakarta:MediaKom.

[4] Soetejo, Jhon. 2012. Jurusan Kilat Mahir Internet. Jakarta: Dunia Komputer.

[5] Madcoms dan Andi. 2008. Adobe Dreamweaver CS3 dan PHP. Yogyakarta:CV.Andi Offset.

[6] Nugraha, Pasca, M dan Rinaldi Munir. 2011. Pengembangan Aplikasi QrCode Generator dan QrCode Reader dari Data Berbentuk Image. Bandung: Kofernsi Nasional Informatika-KNIF 2011, ISSN: 2087-3328.

[7] Rosa. A.S., Shalahuddin, M. 2014. Rekayasa Perangkat Lunak. Bandung:Informatika 